\title{
Goyal-Naqvi Syndrome (Concurrent Trisomy 10p and Terminal 14q Deletion): A Review of the Literature
}

\author{
Chanan Goyal ${ }^{1,2}$, Vivek Goyal ${ }^{3}$, Waqar M. Naqvi ${ }^{4,5}$ \\ 1. Physiotherapy, Datta Meghe Institute of Medical Sciences, Wardha, IND 2. Paediatric Physiotherapy, Government \\ Physiotherapy College, Raipur, IND 3. Department of Anesthesiology, Shri Balaji Institute of Medical Science, Raipur, \\ IND 4. Community Physiotherapy, Mahatma Gandhi Mission School of Physiotherapy, Aurangabad, IND 5. Community \\ Physiotherapy, Mahatma Gandhi Mission Institute of Health Sciences, Navi Mumbai, IND
}

Corresponding author: Chanan Goyal, chanangupta@gmail.com

\begin{abstract}
Goyal-Naqvi syndrome (GNS) is a newly documented clinical entity that comprises trisomy 10p and terminal $14 \mathrm{q}$ deletion, though trisomy 10p and terminal $14 \mathrm{q}$ deletion have been discovered as distinct conditions in 1974 and 1997, respectively. Nevertheless, to date, the total number of reported cases of each of these conditions is estimated to be in double digits. Both manifest as a constellation of features like craniofacial dysmorphism, hypotonia, intellectual impairment and global developmental delay. Characteristic facies include protruded forehead, hypertelorism, epicanthic folds, down slanting palpebral fissures, flat nasal bridge, long philtrum, thin upper lip, carp-shaped mouth, retro-micrognathia and low set ears. Besides, trisomy 10p is strikingly associated with clinodactyly and camptodactyly which aids in clinical diagnosis, apart from other musculoskeletal deformities like hip dysplasia and pes planus. Intersex conditions have been found to commonly co-exist. As other systems also display involvement frequently, trisomy 10p is a discernible multiple congenital anomalies/mental retardation (MCA/MR) syndrome. On the other hand, with terminal 14q deletion, increased risk of certain types of cancer was predicted as specific tumor suppressor genes are lost in the deletion and thus, screening was recommended. Genetic workup using techniques like fluorescence in situ hybridization (FISH), spectral karyotyping (SKY) and chromosomal microarray-based comparative genomic hybridization (CGH) was found to be helpful in diagnosis of trisomy 10p and 14q deletion. Prenatal diagnosis of these conditions has been well documented too. Intrauterine growth retardation has been observed to be related to trisomy 10p. There is a paucity of literature on the management of children diagnosed with trisomy 10p or with terminal 14q deletion. Although management of a child diagnosed with concomitant occurrence of trisomy 10p and terminal 14q deletion by a multidisciplinary approach emphasizing physiotherapeutic intervention has shown remarkable improvement in motor skills, the care of children diagnosed with these genetic aberrations needs further investigation. Documentation of more such cases will help to expand phenotypic spectrum for early identification and to delineate natural history for a life span approach. Early identification and intervention facilitate tapping of the maximum neuroplastic potential for better neurodevelopmental outcomes. We present a review of current literature on this novel syndrome to identify gaps in knowledge to build future research.
\end{abstract}

Review began 06/27/2021 Review ended 07/14/2021 Published 07/26/2021

\section{() Copyright 2021}

Goyal et al. This is an open access article distributed under the terms of the Creative Commons Attribution License CC-BY 4.0., which permits unrestricted use, distribution, and reproduction in any medium, provided the original author and source are credited.
Categories: Neurology, Pediatrics

Keywords: goyal naqvi syndrome, goyal-naqvi syndrome, trisomy 10p, terminal 14q deletion, rare genetic disorder, rare syndrome

\section{Introduction And Background}

Goyal-Naqvi syndrome (GNS) is a recently discovered genetic disorder that is a rare combination of two specific aberrations. GNS refers to a concomitant occurrence of an extra copy of genetic material on the short arm of chromosome 10 (trisomy 10p) and deletion of genetic material in the terminal region on the long arm of chromosome 14 (terminal 14q deletion) [1]. Trisomy 10p can be partial or complete and is rare to be diagnosed. According to a study published a decade ago, only 58 cases of trisomy 10 p were documented by the year 2011 [2], though the first description of the same, dates back to 1974 [3]. Even more rare is the occurrence of terminal 14q deletion, as just 20 cases had been reported in the literature since its discovery in 1997 [4], in accordance with a study published in the year 2009 [5].

The clinical features of GNS are a combination of manifestations that characterize trisomy 10p and terminal $14 \mathrm{q}$ individually. Striking features include hypotonia, intellectual impairment and developmental delay in all domains, namely motor, language, social and adaptive skills. Craniofacial dysmorphism included atypical skull shape, elongated face, protuberant forehead, widely spaced eyes, down slanting palpebral fissures, broad nasal bridge with bulbous nasal tip, low-set ears, long philtrum, thin upper lip, microstomia and retromicrognathia. Camptodactyly and atypical palmar creases were the classical features present in the hands. Other musculoskeletal features included widely abducted hips, bilateral hyperextension of knees and pes planus. Besides, the child displayed frequent extraneous movements of the head and neck [1]. 
Although there is rich literature on phenotype and diagnosis of patients with trisomy 10p and terminal $14 \mathrm{q}$ deletion, a dearth of studies on the management of these patients is present. However, the female child reported with GNS was found to benefit from physiotherapy intervention [1]. We document a review of presently available literature on trisomy 10p and terminal 14q deletion that form the components of GoyalNaqvi syndrome that provides a base of what is known to reveal gaps in knowledge that would help in laying recommendations about research in unexplored avenues.

\section{Review}

PubMed and ScienceDirect databases were searched with keywords Goyal-Naqvi syndrome, trisomy 10p and terminal 14q deletion. Relevant studies in English were considered for the review.

\section{Trisomy 10p}

Prevalence

Trisomy 10 is not as uncommon as trisomy 10p. Trisomy 10p can be either partial or complete. According to a study published in 2012, only five cases of complete trisomy 10p had been documented in the literature till then [6]. The estimated number of total cases reported to date is in double digits as by the year 2011, only 58 cases of trisomy 10p were documented since its first discovery [2].

Phenotype

Trisomy 10p is characterized by craniofacial abnormalities including dolichocephaly/ microcephaly, long face, broad forehead, widely spaced eyes, depressed nasal bridge, high arched palate and prominent ears as well as neurological deficits comprising neurodevelopmental delay and hypotonia [6-23]. Multiple congenital abnormalities are frequently observed namely cleft lip and cleft palate, cardiac manifestations including atrial septal defect, ventricular septal defect, patent ductus arteriosus, musculoskeletal deformities including barrel-shaped chest, genu recurvatum, talipes equinovarus and flexed large joints, integumentary system involvement like marbled skin [6-10,12-16,18,24]. Some striking features in the hand that can aid clinical diagnosis are atypical palmar creases like formation of a triangle, camptodactyly and clinodactyly $[7,11,14,18-20,24]$. The first case report on GNS also reported similar findings in context of hand [1]. It is interesting to note that around $20 \%$ of males presenting with duplication of $10 \mathrm{p}$ displayed intersex condition [7]. Inguinal/umbilical hernia and genital abnormalities like hypospadias, cryptorchidism were observed in multiple cases [11,12,25]. Turner syndrome was associated with trisomy 10p as documented in a study [26]. Despite variation observed over the phenotypic spectrum, trisomy 10p demonstrates discernible multiple congenital anomalies/mental retardation (MCA/MR) syndrome [11,27,28]. In conformation to the case report on GNS, absence of cardiopulmonary malformations has been observed in other previous studies on trisomy $10 \mathrm{p}[1,13-15]$. One of the studies reported features resembling facio-auriculo-vertebral spectrum in a child with trisomy 10p [29].

Diagnosis

Trisomy 10p with or without other genetic aberrations has been diagnosed prenatally in numerous reports [9,10,30-33]. Oligohydramnios and intrauterine growth retardation (IUGR) were significant findings in prenatal investigations [6].

Most of the documented cases have trisomy for distal one-third of 10p [34]. Different methods used for diagnosis or determining parental origin in various studies were fluorescence in situ hybridization (FISH), spectral karyotyping (SKY), chromosomal microarray-based comparative genomic hybridization (CGH) and restriction fragment length polymorphism (RFLP) analysis [35,36]. A ratio of about 2:1 is estimated between the frequencies of balanced and karyotypically normal offspring from carriers in trisomy 10p [37]. For most children diagnosed with trisomy 10p, the carrier was the mother [1,3,7,10,17,18,20,23,30,38-40].

\section{Terminal 14q deletion}

Prevalence

$14 \mathrm{q}$ deletion can be a linear (interstitial or terminal) or ring chromosome deletion. The total number of terminal 14q deletion cases reported since the first description in 1997 is estimated to be in the double digits $[1,4,5]$.

Phenotype

Phenotypic delineation of terminal 14q deletion comprises hypotonia, global developmental delay, facial dysmorphism (frontal bossing, epicanthic folds, blepharophimosis, thin upper lip vermillion, wide philtrum, triangular/fish-shaped mouth, micrognathia) as was observed in the child with GNS too [1,41-47].

Musculoskeletal manifestations like joint laxity, scoliosis, arthrogryposis multiplex congenita have also been 
noted as striking features [48]. An extremely mild form of holoprosencephaly was documented with terminal $14 \mathrm{q}$ deletion, which is otherwise common with interstitial deletion $[49,50]$. Clinical features of interstitial $14 \mathrm{q}$ deletion that resemble those of terminal deletion are craniofacial dysmorphism like microcephaly, widely spaced eyes, epicanthal folds, long-smooth philtrum and tooth agenesis, apart from neurological manifestations like hypotonia and delayed psychomotor development. Hydronephrosis was a finding in ultrasound examination of kidney too [51]. This was similar to the case reported with GNS where fetal ultrasound revealed edema in unilateral kidney [1]. Chromosome 14q carries tumor suppressor genes which on deletion may inflate vulnerability to renal cancer. $L 2 H G D H$ is suggested to be one of the tumor suppressor genes that is a target of $14 \mathrm{q}$ deletion [52]. Besides, higher risk of meningiomas and nonHodgkin's lymphoma has been predicted $[53,54]$. Thus, regular screening with high suspicion should be undertaken in patients with $14 \mathrm{q}$ deletion $[55]$.

Diagnosis

In a study, prenatal diagnosis of partial monosomy $14 \mathrm{q}$ with partial monosomy $5 \mathrm{p}$ was documented. Fetal ultrasound demonstrated IUGR apart from single umbilical artery, nuchal edema and microcephaly at 23 weeks of gestation. Other methods and techniques used, thereafter, were amniocentesis, whole-genome array comparative genomic hybridization on non-cultured amniocytes, quantitative fluorescent polymerase chain reaction (PCR) analysis on parental blood and non-cultured cord blood. The study concluded that such a combination of genetic variability can be gauged prenatally [56]. Prenatal diagnosis of 14q deletion has been documented in other studies also $[48,57]$. The mother has been reported to be the carrier of the translocation in children with terminal $14 \mathrm{q}$ deletion $[1,58]$.

\section{Therapeutic intervention}

Supportive medical management like vitamin D, iron and folic acid supplementation for the child diagnosed with GNS has been documented [1]. The physiotherapy intervention based on the principles of neurodevelopmental treatment in which the child actively participates in functional activities was reported to bring significant changes in the motor skills of the child diagnosed with GNS as was objectively measured by gross motor function measure (GMFM). Transitions like supine to sit and sit to stand were facilitated. Vestibular and proprioceptive inputs were given. Stabilizing pressure input orthosis for the trunk was found to be beneficial in maintaining posture that was otherwise difficult due to truncal hypotonia [1]. Previous studies on other rare syndromes have also shown remarkable benefits of physiotherapy and use of orthoses on motor function $[59,60]$. Besides, genetic counselling of the parents must be undertaken as preconception advice in the future [1].

\section{Conclusions}

Techniques for prenatal diagnosis of an extensive list of genetic disorders are available. Simpler forms of screening tests that predict risk of a wide range of aberrations are available but still need further research to increase sensitivity and specificity so that relevant tests for diagnosis can be applied for the pregnant women who need it. Nevertheless, genetic disorders like GNS are expected to remain largely undiagnosed until postnatal life or infancy owing to their rare occurrence and lack of resources, especially in developing and underdeveloped nations. Thus, identification in the early days of life by high degree of suspicion for a child with dysmorphic facies and developmental delay becomes needful for early intervention to tap the highest possible potential of neuroplasticity of the young brain. Though definitive diagnosis after detailed genetic work-up paves the way for streamlined management and prediction of prognosis, therapeutic intervention must not be delayed while that is awaited. Besides, the description of phenotypic spectrum in the literature on patients with similar genotype helps to delineate guidelines for clinical diagnosis. Definitive management and natural history of this rare syndrome must be documented in future studies.

\section{Additional Information}

\section{Disclosures}

Conflicts of interest: In compliance with the ICMJE uniform disclosure form, all authors declare the following: Payment/services info: All authors have declared that no financial support was received from any organization for the submitted work. Financial relationships: All authors have declared that they have no financial relationships at present or within the previous three years with any organizations that might have an interest in the submitted work. Other relationships: All authors have declared that there are no other relationships or activities that could appear to have influenced the submitted work.

\section{References}

1. Goyal C, Goyal V, Naqvi WM: A rare and unusual case of trisomy 10p with terminal 14q deletion: a multidisciplinary approach. Cureus. 2021, 13:e15459. 10.7759/cureus.15459

2. Szabó GP, Knegt AC, Ujfalusi A, Balogh E, Szabó T, Oláh É: Subtelomeric 6.7 Mb trisomy 10p and 5.6 Mb monosomy 21q detected by FISH and array-CGH in three related patients. Am J Med Genet A. 2012, 158A:869-76. 10.1002/ajmg.a.35236

3. Schleiermacher E, Schliebitz U, Rompe G, Steffens C, Schmidt U: Brother and sister with trisomy 10p: a new 
syndrome. Humangenetik. 1974, 23:163-72. 10.1007/BF00285102

4. Ortigas AP, Stein CK, Thomson LL, Hoo JJ: Delineation of 14q32.3 deletion syndrome. J Med Genet. 1997, 34:515-7. 10.1136/jmg.34.6.515

5. Schlade-Bartusiak K, Ardinger H, Cox DW: A child with terminal 14q deletion syndrome: consideration of genotype-phenotype correlations. Am J Med Genet A. 2009, 149A:1012-8. 10.1002/ajmg.a.32752

6. Lozić B, Culić V, Lasan R, Tomasović M, Samija RK, Zemunik T: Complete trisomy 10p resulting from an extra stable telocentric chromosome. Am J Med Genet A. 2012, 158A:1778-81. 10.1002/ajmg.a.35384

7. Gonzalez CH, Billerbeck AE, Takayama LC, Wajntal A: Duplication 10p in a girl due to a maternal translocation t(10;14) (p11:p12). Am J Med Genet. 1983, 14:159-67. 10.1002/ajmg.1320140122

8. Berend SA, Shaffer LG, Bejjani BA: Pure trisomy 10p involving an isochromosome 10p. Clin Genet. 1999, 55:367-71. 10.1034/j.1399-0004.1999.550512.x

9. Clement SJ, Leppig KA, Jarvik GP, Kapur RP, Norwood TH: Trisomy 10p: report of an unusual mechanism of formation and critical evaluation of the clinical phenotype. Am J Med Genet. 1996, 65:3-197. 10.1002/(SICI)1096-8628(19961028)65:3<197::AID-AJMG5>3.0.CO;2-N

10. Hengstschläger M, Bettelheim D, Repa C, Lang S, Deutinger J, Bernaschek G: A fetus with trisomy 9p and trisomy 10p originating from unbalanced segregation of a maternal complex chromosome rearrangement $\mathrm{t}(4 ; 10 ; 9)$. Fetal Diagn Ther. 2002, 17:243-6. 10.1159/000063401

11. Schwartz S, Cohen MM, Panny SR, Beisel JH, Vora S: Duplication of chromosome 10p: confirmation of regional assignments of platelet-type phosphofructokinase. Am J Hum Genet. 1984, 36:750-9.

12. Slinde S, Hansteen IL: Two chromosomal syndromes in the same family: monosomy and trisomy for part of the short arm of chromosome 10. Eur J Pediatr. 1982, 139:153-7. 10.1007/BF00441502

13. Aller V, Abrisqueta JA, Pérez-Castillo A, del Mazo J, Martín-Lucas MA, de Torres ML: Trisomy 10p due to a de novo t(10p;13p). Hum Genet. 1979, 46:129-34. 10.1007/BF00291912

14. Delicado A, Pajares IL, Vicente P, Hawkins F: Familial translocation t(10;21)(q22;q22). Hum Genet. 1979, 50:253-8. 10.1007/BF00399390

15. Grosse KP, Schwanitz G, Singer H, Wieczorek V: Partial trisomy 10p. Humangenetik. 1975, 29:141-4. 10.1007/BF00430351

16. Dallapiccola B, Chessa L, Vignetti P, Ferrante E, Gandini E: Increased HK1 activity levels in the red cells of a patient with a de novo trisomy 10p: t(Y;10)(p11;p12). Hum Genet. 1979, 50:45-9. 10.1007/BF00295588

17. de Chieri P, Spatuzza E, Bonich JM: Brother and sister with trisomy 10p. 46,XY,(22p+)mat; 46,XX,(22p+)mat . Hum Genet. 1978, 45:71-5. 10.1007/BF00277575

18. Cantu JM, Salamanca F, Buentello L, Carnevale A, Armendares S: Trisomy 10p. A report of two cases due to a familial translocation rcp (10;21) (pII;pII). Ann Genet. 1975, 18:5-11.

19. Herva R, Korhonen S, Haapala K, Timonen E: Trisomy 10p produced by recombination involving complex paternal translocation between chromosomes 1 and 10. Clin Genet. 1983, 24:50-3. 10.1111/j.13990004.1983.tb00069.x

20. Ohba K, Ohdo S, Sonoda T: Trisomy 10p syndrome owing to maternal pericentric inversion. J Med Genet. 1990, 27:264-6. 10.1136/jmg.27.4.264

21. Johnson G, Bachman R, Roed T, Riddervold P: Partial trisomy 10p and familial translocation t(7;10) (p22;p12). Hum Genet. 1977, 35:353-6. 10.1007/BF00446626

22. Seiberth V, Kachel W, Knorz MC, Liesenhoff H: Ophthalmic findings in partial monosomy 4p (Wolf syndrome) in combination with partial trisomy 10p. Am J Ophthalmol. 1994, 117:411-3. 10.1016/s00029394(14)73161-7

23. Stengel-Rutkowski S, Murken JD, Frankenberger R, Riechert M, Spiess H, Rodewald A, Stene J: New chromosomal dysmorphic syndromes. Eur J Pediatr. 1977, 126:109-25. 10.1007/BF00442193

24. Rodewald A, Stengel-Rutkowski S: The dermatoglyphic pattern of the trisomy 10p syndrome. Clin Genet. 1978, 14:330-7. 10.1111/j.1399-0004.1978.tb02098.x

25. Saiga T, Hashimoto K, Kimura N, Ono H, Hiai H: Trisomy 10p and translocation of $10 \mathrm{q}$ to $4 \mathrm{p}$ associated with selective dysgenesis of IgA-producing cells in lymphoid tissue. Pathol Int. 2007, 57:37-42. 10.1111/j.14401827.2007.02054.x

26. Grossi A, Palma A, Zanni G, Novelli A, Loddo S, Cappa M, Fierabracci A: Multiorgan autoimmunity in a Turner syndrome patient with partial monosomy 2q and trisomy 10p. Gene. 2013, 515:439-43. 10.1016/j.gene.2012.12.007

27. Courtens W, Wuyts W, Scheers S, et al.: A de novo subterminal trisomy 10p and monosomy 18q in a girl with MCA/MR: case report and review. Eur J Med Genet. 2006, 49:402-13. 10.1016/j.ejmg.2006.01.001

28. Snyder FF, Lin CC, Rudd NL, Shearer JE, Heikkila EM, Hoo JJ: A de novo case of trisomy 10p: gene dosage studies of hexokinase, inorganic pyrophosphatase and adenosine kinase. Hum Genet. 1984, 67:187-9. 10.1007/BF00272998

29. Dabir TA, Morrison PJ: Trisomy 10p with clinical features of facio-auriculo-vertebral spectrum: a case report. Clin Dysmorphol. 2006, 15:25-7. 10.1097/01.mcd.0000181606.63005.50

30. Nakagome Y, Kobayashi H: Trisomy of the short arm of chromosome 10 . J Med Genet. 1975, 12:412-4. 10.1136/jmg.12.4.412

31. Yunis E, Silva R, Giraldo A: Trisomy 10p. Ann Genet. 1976, 19:57-60.

32. Gunduz C, Cogulu O, Sagol S, Zekioglu O, Ozkinay C, Ozkinay F: Prenatal detection of a pure trisomy 10p case. Prenat Diagn. 2003, 23:356-8. 10.1002/pd.591

33. Sung PL, Chang SP, Wen KC, et al.: Small supernumerary marker chromosome originating from chromosome 10 associated with an apparently normal phenotype. Am J Med Genet A. 2009, 149A:2768-74. 10.1002/ajmg.a.32878

34. Boon C, Markello T, Jackson-Cook C, Pandya A: Partial trisomy 10 mosaicism with cutaneous manifestations: report of a case and review of the literature. Clin Genet. 1996, 50:417-21. 10.1111/j.13990004.1996.tb02399.x

35. Chen Z, Meloni-Ehrig A, Palumbos JC, Guan XY, Carroll KL, Dent KM, Carey JC: Pure trisomy 10p resulting from an extra ring chromosome: characterization by methods of advanced molecular cytogenetics. Am J Med Genet. 2001, 102:379-82. 10.1002/ajmg.1470 
36. Granata P, Mazzola D, Righi R, et al.: Molecular cytogenetics, RFLP analysis and clinical characterization of a de novo trisomy 10p case. Ann Génétique. 2000, 43:45-50. 10.1016/s0003-3995(00)00014-9

37. Stene J, Stengel-Rutkowski S: Genetic risks for familial reciprocal translocations with special emphasis on those leading to 9p, 10p and 12p trisomies. Ann Hum Genet. 1982, 46:41-74. 10.1111/j.14691809.1982.tb00694.x

38. Hustinx TW, Ter Haar BG, Scheres JM, Rutten FJ: Trisomy for the short arm of chromosome No. 10. Clin Genet. 1974, 6:408-15. 10.1111/j.1399-0004.1974.tb02264.x

39. Back E, Vogel W, Hertel C, Schuchmann L: Trisomy 10p due to t $(5 ; 10)(\mathrm{p} 15 ; \mathrm{p} 11)$ segregating in a large sibship. Hum Genet. 1978, 41:11-7. 10.1007/BF00278867

40. Lurie IW, Lazjuk GI, Gurevich DB, Kravtzoa GI, Nedzved MK, Shved IA: Partial trisomy 10p in two generations. Hum Genet. 1978, 41:235-41. 10.1007/BF00273107

41. van Karnebeek CD, Quik S, Sluijter S, Hulsbeek MM, Hoovers JM, Hennekam RC: Further delineation of the chromosome 14q terminal deletion syndrome. Am J Med Genet. 2002, 110:65-72. 10.1002/ajmg.10207

42. Salter CG, Baralle D, Collinson MN, Self JE: Expanding the ocular phenotype of $14 \mathrm{q}$ terminal deletions: a novel presentation of microphthalmia and coloboma in ring 14 syndrome with associated 14q32.31 deletion and review of the literature. Am J Med Genet A. 2016, 170A:1017-22. 10.1002/ajmg.a.37436

43. Ader F, Heide S, Marzin P, et al.: A 14q distal chromoanagenesis elucidated by whole genome sequencing . Eur J Med Genet. 2020, 63:103776. 10.1016/j.ejmg.2019.103776

44. Chen CP, Chern SR, Lin SP, et al.: A paternally derived inverted duplication of distal 14q with a terminal 14q deletion. Am J Med Genet A. 2005, 139A:146-50. 10.1002/ajmg.a.30997

45. Bağci G, Cetin GO, Semerci N, Toruner GA, Cinbiş M: Terminal 14q deletion with unbalanced $t(Y ; 14)$ (q12;q32) translocation. Clin Dysmorphol. 2012, 21:37-41. 10.1097/MCD.0b013e32834d6ba3

46. Maurin ML, Brisset S, Le Lorc'h M, et al.: Terminal 14q32.33 deletion: genotype-phenotype correlation. Am J Med Genet A. 2006, 140:2324-9. 10.1002/ajmg.a.31438

47. Schneider A, Benzacken B, Guichet A, et al.: Molecular cytogenetic characterization of terminal 14q32 deletions in two children with an abnormal phenotype and corpus callosum hypoplasia. Eur J Hum Genet. 2008, 16:680-7. 10.1038/sj.ejhg.5201977

48. Chen CP, Chang YL, Chern SR, et al.: Prenatal diagnosis of partial trisomy 3q (3q27.3 $\rightarrow$ qter) and partial monosomy $14 \mathrm{q}(14 \mathrm{q} 31.3 \rightarrow \mathrm{qter})$ of paternal origin associated with fetal hypotonia, arthrogryposis, scoliosis and hyperextensible joints. Gene. 2013, 516:132-7. 10.1016/j.gene.2012.12.052

49. Della Giustina E, Iodice A, Spagnoli C, et al.: "Minimal" holoprosencephaly in a $14 \mathrm{q}$ deletion syndrome patient. Am J Med Genet A. 2017, 173:3216-20. 10.1002/ajmg.a.38378

50. Segawa Y, Itokazu N, Hirose A, Nakagawa S, Takashima S: A case of partial 14q- with facial features of holoprosencephaly and hydranencephaly. Pediatr Neurol. 2007, 37:51-4. 10.1016/j.pediatrneurol.2007.02.010

51. Petek E, Plecko-Startinig B, Windpassinger C, Egger H, Wagner K, Kroisel PM: Molecular characterisation of a $3.5 \mathrm{Mb}$ interstitial 14q deletion in a child with several phenotypic anomalies. J Med Genet. 2003, 40:e47. 10.1136/jmg.40.4.e47

52. Shenoy N: HIF1 $\alpha$ is not a target of $14 \mathrm{q}$ deletion in clear cell renal cancer . Sci Rep. 2020, 10:17642. 10.1038/s41598-020-74631-7

53. Battu S, Kumar A, Pathak P, et al.: Clinicopathological and molecular characteristics of pediatric meningiomas. Neuropathology. 2018, 38:22-33. 10.1111/neup.12426

54. Kristoffersson U, Heim S, Johnsson A, Mandahl N, Olsson H, Akerman M, Mitelman F: Deletion of 14q in non-Hodgkin's lymphoma. Eur J Haematol. 1990, 44:261-4. 10.1111/j.1600-0609.1990.tb00390.x

55. Shen C, Beroukhim R, Schumacher SE, Zhou J, Chang M, Signoretti S, Kaelin WG Jr: Genetic and functional studies implicate HIF1 $\alpha$ as a 14q kidney cancer suppressor gene. Cancer Discov. 2011, 1:222-35. 10.1158/2159-8290.CD-11-0098

56. Chen $\mathrm{CP}, \mathrm{Fu} \mathrm{CH}$, Chern SR, et al.: De novo unbalanced translocation resulting in monosomy for distal $5 \mathrm{p}$ $(5 \mathrm{p} 14.1 \rightarrow$ pter $)$ and $14 \mathrm{q}(14 \mathrm{q} 32.31 \rightarrow$ qter $)$ associated with fetal nuchal edema, microcephaly, intrauterine growth restriction, and single umbilical artery: prenatal diagnosis and molecular cytogenetic characterization. Taiwan J Obstet Gynecol. 2013, 52:401-6. 10.1016/j.tjog.2013.06.005

57. Chen CP, Wang LK, Chern SR, et al.: Prenatal diagnosis and molecular cytogenetic characterization of a de novo 3.19-Mb chromosome 14q32.13-q32.2 deletion of paternal origin. Taiwan J Obstet Gynecol. 2020, 59:766-9. 10.1016/j.tjog.2020.07.026

58. Zrnová E, Vranová V, Soukalová J, Slámová I, Vilémová M, Gaillyová R, Kuglík P: Unique combination of 22q11 and 14qter microdeletion syndromes detected using oligonucleotide array-CGH. Mol Syndromol. 2012, 2:88-93. 10.1159/000335334

59. Goyal C, Naqvi WM, Sahu A: An atypical case of febrile infection-related epilepsy syndrome following acute encephalitis: impact of physiotherapy in regaining locomotor abilities in a patient with neuroregression. Pan Afr Med J. 2020, 36:101. 10.11604/pamj.2020.36.101.23855

60. Goyal C, Naqvi W, Sahu A: Xia-Gibbs Syndrome: a rare case report of a male child and insight into physiotherapy management. Cureus. 2020, 12:e9622. 10.7759/cureus.9622 